\title{
Tarefas exploratórias e investigativas: uma análise dos trabalhos publicados no XI e XII Encontro Nacional de
}

\section{Educação Matemática}

Exploratory and investigative tasks: an analysis of the works published in the XI and XII Encontro Nacional de Educação Matemática

\author{
Ana Maria Foss ${ }^{1}$ \\ Paulo Wichnoski ${ }^{2}$ \\ Tânia Stella Bassoi ${ }^{3}$
}

\section{Resumo}

Assumindo os aspectos da pesquisa qualitativa, este artigo explicita uma análise dos trabalhos publicados nas edições XI e XII do Encontro Nacional de Educação Matemática - ENEM como foco nas tarefas de Investigação Matemática. Com isso, buscamos responder as algumas questões norteadoras, tais como: Há especificidades que permitam distinguir as tarefas investigativas das tarefas exploratórias? Que conteúdos foram abordados nestas tarefas? Em que contextos - real, semirreal ou matemático - se inserem? Como síntese do percebido e articulado afirmamos que nas edições do evento supramencionado, as tarefas se mostraram predominantemente exploratórias, situadas no contexto puramente matemático e abordaram conteúdos relativos a Geometria. Também inferimos que as tarefas analisadas e por nós classificadas como investigativas não apresentaram questões a serem respondidas, já as tarefas por nós classificadas como exploratórias apresentaram-se compostas por encaminhamentos que induzem o aluno a perceber algo que sempre acontece ou não, as questões seguintes o induzem a concluir $\mathrm{e}$ generalizar os resultados identificados.

Palavras-chave: Investigação matemática. Tarefas de investigação matemática. Pesquisa qualitativa.

\section{Introdução}

No itinerário de formação inicial, a primeira autora desse trabalho empreendeu um estudo no âmbito de um projeto Iniciação Científica Voluntário

\footnotetext{
${ }^{1}$ Discente do Curso de Licenciatura em Matemática - UNIOESTE, campus de Cascavel, bolsista voluntária em um Projeto de Iniciação Científica, anafoss@bol.com.br.

${ }^{2}$ Doutorando em Educação em Ciências e Educação Matemática - UNIOESTE, campus de Cascavel, wichnoski@gmail.com.

3 Doutora em Educação, professora associada do colegiado de Matemática e do Programa de PósGraduação em Educação em Ciências e Educação Matemática - UNIOESTE, campus de Cascavel, tstellabassoi@gmail.com.
} 
tendo a Investigação Matemática como foco de estudos. O projeto teve duração de um ano e foi orientado pela terceira a autora e coorientado pelo segundo autor deste artigo.

Em contato com a teoria e com relatos de aplicações de tarefas de Investigação Matemática, desvelou-se a carência de trabalhos que discutam as principais diferenças entre as tarefas exploratórias e investigativas, bem como a não preocupação em seguir a classificação posta na literatura sobre o tema. Desse modo, decidimos, além do estudo teórico inicialmente planejado, nos debruçar sobre esse aspecto, buscando elucidar as características de uma tarefa exploratória e de uma tarefa investigativa.

Buscando pelos modos de ser possível elencar as diferenças entre esses dois tipos de tarefas, aventamos a possibilidade de olhar para os trabalhos, comunicações científicas, relatos de experiências e minicursos, publicados no XI e XII ENEM, procurando por tarefas de Investigação Matemática neles apresentadas.

Ao efetuar esse movimento de busca outras questões foram emergindo e se prestaram norteadoras de pesquisa. Essas questões podem ser assim sintetizadas: Há especificidades que permitam distinguir as tarefas investigativas das tarefas exploratórias? Que conteúdos foram abordados nestas tarefas? Em que contextos - real, semirreal ou matemático - se inserem?

Em face disso, abrimos a possibilidade de discutir as tarefas de Investigação Matemática para além de uma classificação, mesmo que em nível exploratório, de modo a lançar luzes sobre pontos obscuros e que ainda carecem de reflexões como, por exemplo, "à ancoragem deste conceito - o de Investigação Matemática - na matemática pura ou aplicada" (PONTE, 2003, p. 1, inserção nossa).

Desse preâmbulo, passamos a apresentar uma síntese compreensiva acerca da Investigação Matemática na Educação Matemática.

\section{Investigação Matemática: uma síntese compreensiva}

Atualmente, para quem vivencia as aulas de matemática, é evidente que o paradigma do exercício, discutido por Skovsmose (2000), é predominante. Nele, a 
concepção assumida é de que a aprendizagem se dá por meio da repetição de técnicas, procedimentos e algoritmos para a resolução de exercícios propostos exclusivamente pelo professor. Também se têm a compreensão de que o professor deve deflagrar o conteúdo, ou seja, os alunos são passivos nesse processo.

Tentando romper com esse paradigma, Skovsmose (2000) propõe que o ensino deve mover-se para o paradigma da investigação, no qual a partir de uma situação aberta ou semiaberta, os alunos, metaforicamente, ajam como matemáticos, levantando questões para investigar, formulando e testando hipóteses e por fim validando seus resultados, redescobrindo a Matemática.

Para Ponte, Brocardo e Oliveira (2013, p. 23)

O conceito de investigação matemática, como atividade de ensinoaprendizagem, ajuda a trazer para a sala de aula o espírito da atividade Matemática genuína, constituindo, por isso, uma poderosa metáfora educativa. O aluno é chamado a agir como um matemático, não só na formulação de questões e conjecturas e na realização de provas e refutações, mas também na apresentação de resultados e na discussão e argumentação com os seus colegas e o professor.

Isso nos remete a ideia de que a Investigação Matemática está relacionada com a atividade de comunicação, argumentação, pesquisa, seleção, organização, criatividade, enfocando conceitos e objetos matemáticos. É, portanto, "uma atividade que está no cerne da produção do conhecimento em matemática [...] possui relações com o fazer matemática" (WICHNOSKI; KLÜBER, 2017a, p. 169).

Wichnoski e Klüber (2015, p. 72) afirmam que "a Investigação Matemática no âmbito da Educação Matemática repousa sobre uma estrutura básica, constituída por aspectos fundamentais como a matemática, o ensino, a aprendizagem, a comunicação e atividades investigativas".

Todavia, a que tipo de atividades se faz menção ao propor Investigações Matemáticas? A que investigação se reporta ao falar de conjecturas, erros, argumentação, pesquisa? Parece que estes substantivos são características presentes em toda a atividade matemática e, de fato estão.

Todavia, ao que pese à Investigação Matemática como metodologia de ensino, não basta necessariamente atender ao princípio da investigação - ato ou 
ação de inquirir, descobrir -, mas que este princípio de desenvolva, entre outras especificidades, em face de tarefas próprias e com características peculiares, caso contrário, toda tarefa de matemática pode ser considerada uma tarefa de Investigação Matemática.

Ponte (2003) apresenta dois tipos de tarefas de Investigação Matemática: tarefas investigativas e tarefas exploratórias. Segundo este autor, as tarefas investigativas são abertas e com grau de dificuldade elevado, enquanto que uma tarefa exploratória possui menor grau de dificuldade e estrutura aberta. Dito de outro modo, questões relativamente estruturadas (tarefas exploratórias) e questões abertas (tarefas investigativas).

No entanto, Ponte (2003) ressalta que as tarefas exploratórias não se reduzem a uma simples lista de exercícios, nos quais os itens são independentes e, embora os itens pareçam repetitivos, há um raciocínio que pode ser feito a partir de todos eles e que tem a ver com certas regularidades. As questões mais estruturadas podem também constituir-se num trabalho de preparação e ambientação com o paradigma investigativo, almejando as questões mais abertas.

Para Ponte (2005)

Entre as tarefas de exploração e as de investigação a diferença está [...] no grau de desafio. Se o aluno puder começar a trabalhar desde logo, sem muito planejamento, estaremos perante uma tarefa de exploração. Caso contrário, será talvez melhor falar em tarefa de investigação (PONTE, 2005, p. 18).

Ao ser caracterizar uma tarefa investigativa como aberta e difícil, o termo difícil está associado ao grau de aberturada tarefa, já que essas tarefas exigem do aluno maior autonomia e do professor um leque maior de conhecimentos matemáticos. Porém, o próprio autor reconhece que a dificuldade é relativa ao investigador ao afirmar que "é complicado saber à partida qual o grau de dificuldade que uma tarefa aberta terá para um certo grupo de alunos" (PONTE, 2003, p. 5).

Nesse sentido, admitimos para este trabalho o grau de abertura para a investigação que a tarefa proporciona, isto é, maior abertura e possibilidades de investigação (tarefa investigativa), menor abertura e possibilidades de investigação (tarefa exploratória). O Quadro 1 abaixo exemplifica o nosso entendimento. 


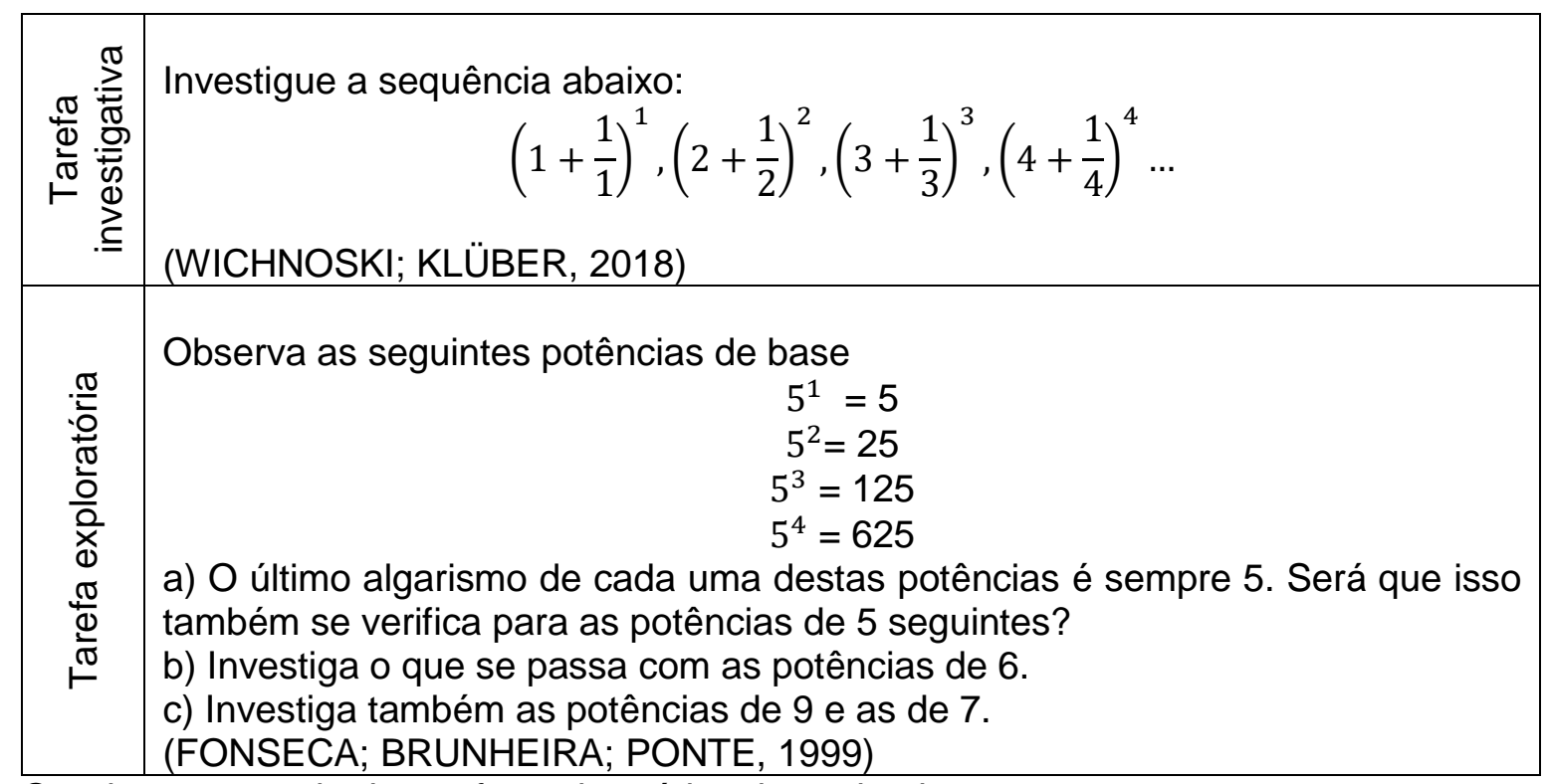

Quadro 1: exemplo de tarefa exploratória e investigativa

Fonte: os autores

Na próxima seção explicitamos a metodologia utilizada em busca de, senão responder, aclarar as questões norteadoras da pesquisa, a saber: Há especificidades que permitam distinguir as tarefas investigativas das tarefas exploratórias? Que conteúdos foram abordados nestas tarefas? Em que contextos - real, semirreal ou matemático - se inserem?

\section{Metodologia e procedimentos}

O trabalho foi realizado de acordo com os pressupostos da pesquisa exploratória e da pesquisa qualitativa. A pesquisa exploratória, de acordo com Gil (1999), tem como finalidade esclarecer conceitos e ideias, tem como objetivo fornecer uma visão mais ampla acerca de determinado tema, visto que esse é pouco explorado e podem envolver levantamentos bibliográficos e documentais, entrevistas não padronizadas e estudos de caso.

A pesquisa qualitativa, segundo Gerhardt e Silveira (2009), preocupa-se em explicar e compreender aspectos da realidade que não podem ser quantificados.

Ou seja, ela trabalha com o universo de significados, motivos, aspirações, crenças, valores e atitudes, o que corresponde a um espaço mais profundo das 
relações, dos processos e dos fenômenos que não podem ser reduzidos à operacionalização de variáveis (MINAYO, 2001, p. 21).

Nesse sentido, buscamos por aquilo que de significativo se mostra ao olhar de quem pesquisa, entendendo os materiais de análises, os dados e os resultados como indicadores de ideias e valores construídos social e historicamente. Buscamos por aspectos que, em face das interrogações construídas na pesquisa, sejam dotados de significado e possam revelar-se esclarecedores daquilo que buscamos, mesmo em nível exploratório.

Para isso procedemos às comunicações científicas, relatos de experiências e minicursos publicados no Encontro Nacional de Educação Matemática (ENEM) das duas últimas edições do evento (XI e XII) em que tratavam da Investigação Matemática com o objetivo de selecionar tarefas exploratórias e investigativas que porventura estivessem nestes trabalhos.

A seleção do material de análise se deu por meio de leitura dos títulos e das palavras-chave destes trabalhos, identificando palavras relacionadas a Investigação Matemática, como por exemplo, investigação, tarefas exploratórias. Após uma pré-classificação, efetuamos a leitura dos trabalhos na íntegra e selecionamos aqueles que explicitaram trazer em seu conteúdo tarefas de Investigação Matemática.

Desse exercício obtivemos um universo de 37 trabalhos, sendo 24 trabalhos da XI edição do evento e 13 na XII edição, como ilustra o Gráfico 1 a seguir:

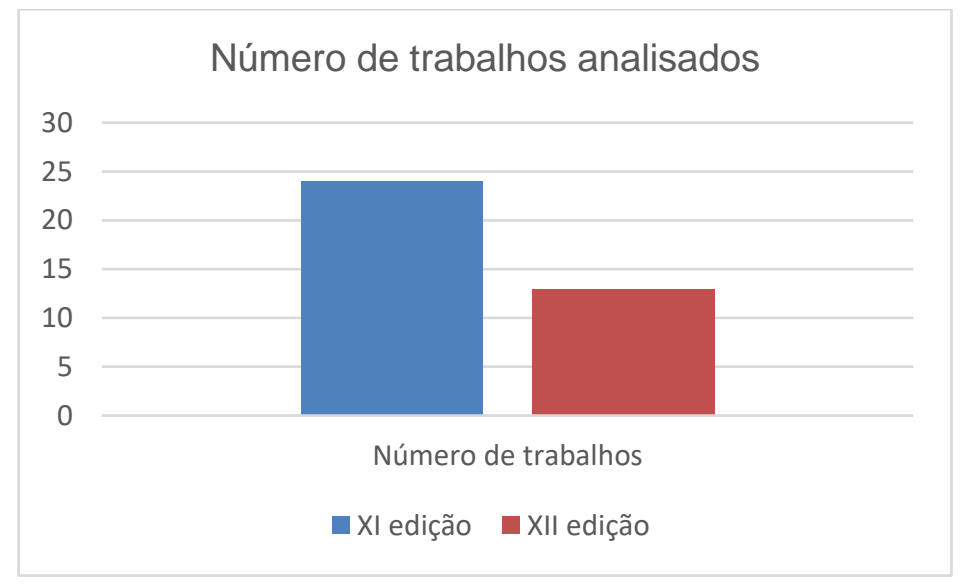

Gráfico 1: Número de trabalhos analisados Fonte: os autores 
Em seguida olhamos para as tarefas contidas nestes trabalhos e analisamolas em face do nosso entendimento sobre tarefas exploratórias e investigativas, classificando-as em dois grupos: 1) tarefas investigativas e 2) tarefas exploratórias. Dado limite de páginas, não é possível expor todas as tarefas identificadas e o modo que encontramos para o leitor acessá-las foi explicitando o título do trabalho publicado no XI ou XII ENEM, a página onde se encontra a descrição da tarefa e o link de acesso na rede, na seguinte ordem: título do trabalho/página/link de acesso. Todas essas informações encontram-se nos Quadros 3 e 4, em anexo.

Nos debruçamos sobre estes dois grupos de tarefas e, num exercício reflexivo e intersubjetivo nos perguntamos: Há especificidades que permitam distinguir as tarefas investigativas das tarefas exploratórias? Que conteúdos foram abordados nestas tarefas? Em que contextos - real, semirreal ou matemático - se inserem? A síntese a que chegamos é conteúdo da próxima seção.

\section{Descrição do percebido como movimento de análise}

Quanto ao número de tarefas nota-se uma maior quantidade de tarefas exploratórias em relação às investigativas. Isso pode encontrar justificativas na insegurança do professor no trabalho com a Investigação Matemática ou na pouca experiência dos professores e alunos nesse tipo de trabalho.

A insegurança por parte do professor ocorre quando o trabalho com a Investigação Matemática é desenvolvido pelas primeiras vezes, uma vez que há mudanças na função desempenhada em sala de aula, deixando de ser o detentor do conhecimento para auxiliar e motivar os alunos em suas investigações. Além disso, o grau de abertura das tarefas investigativas, em relação às exploratórias, permitem aos alunos percorrer diferentes caminhos e consequentemente chegar em resultados diferentes dos previstos pelo próprio professor.

Essa insegurança também encontra justificativas na citação de Ponte (2006, p.14), ao mencionar que

A verdade é que uma aula com tarefas de natureza exploratório-investigativa é mais complicada de gerir do que uma aula baseada na exposição de matéria e na realização de exercícios, dada a imprevisibilidade das propostas e questões 
que os estudantes podem colocar. Acresce, ainda, que os estudantes à partida não sabem como trabalhar neste tipo de tarefa e precisam que o professor os ajude a fazer essa aprendizagem.

Já a não experiência dos alunos com tarefas de Investigação Matemática, pode ser consequência de as aulas de Matemática serem, geralmente, pautadas na metodologia tradicional, em que o professor é o detentor do conhecimento e o aluno deve absorvê-lo e repetir técnicas e procedimentos. Assim, o professor, ao perceber que os alunos não estão habituados com tarefas de Investigação Matemática prefere optar por tarefas exploratórias, as quais exigem do aluno menor autonomia, já que essas indicam alguns caminhos para a investigação, ao contrário das tarefas investigativas que têm um grau de abertura maior exigindo dos alunos maior autonomia.

Skovsmose (2000, p. 68) traz os cenários para investigação como "um ambiente que pode dar suporte a um trabalho de investigação" definindo-o como "aquele que convida os alunos a formularem questões e procurarem explicações" (p. 71). Nesse sentido, entendemos que as tarefas de Investigação Matemática atendem aos critérios propostos por Skovsmose (2000) e por isso podemos classificá-las segundo o contexto que a tarefa se insere.

Skovsmose (2000) define três contextos: referências à matemática pura, referências à semirrealidade e referências à realidade. Referências à matemática pura refere-se ao contexto puramente matemático, ou seja, traz a simbologia própria da Matemática e trata somente de objetos matemáticos. Já a semirrealidade referem a uma realidade construída, por exemplo, por um autor de um livro didático de Matemática; os dados e as situações são fictícias. A referência à realidade diz de contextos e situações verídicas, ou seja, os dados a serem investigados são reais.

Tendo em vista estes três possíveis cenários para a realização de uma investigação matemática, as tarefas presentes nos trabalhos analisados se configuraram em diferentes cenários. Houve a ocorrência de tarefas exploratórias e investigativas construídas no contexto puramente matemático, com predominância nas tarefas investigativas. As tarefas que fazem referência à 
semirrealidade se mostraram somente do tipo exploratório. Não houve tarefas construídas no contexto real. O Gráfico 2 abaixo sintetiza a ocorrências das tarefas em cada cenário proposto por Skovsmose (2000).

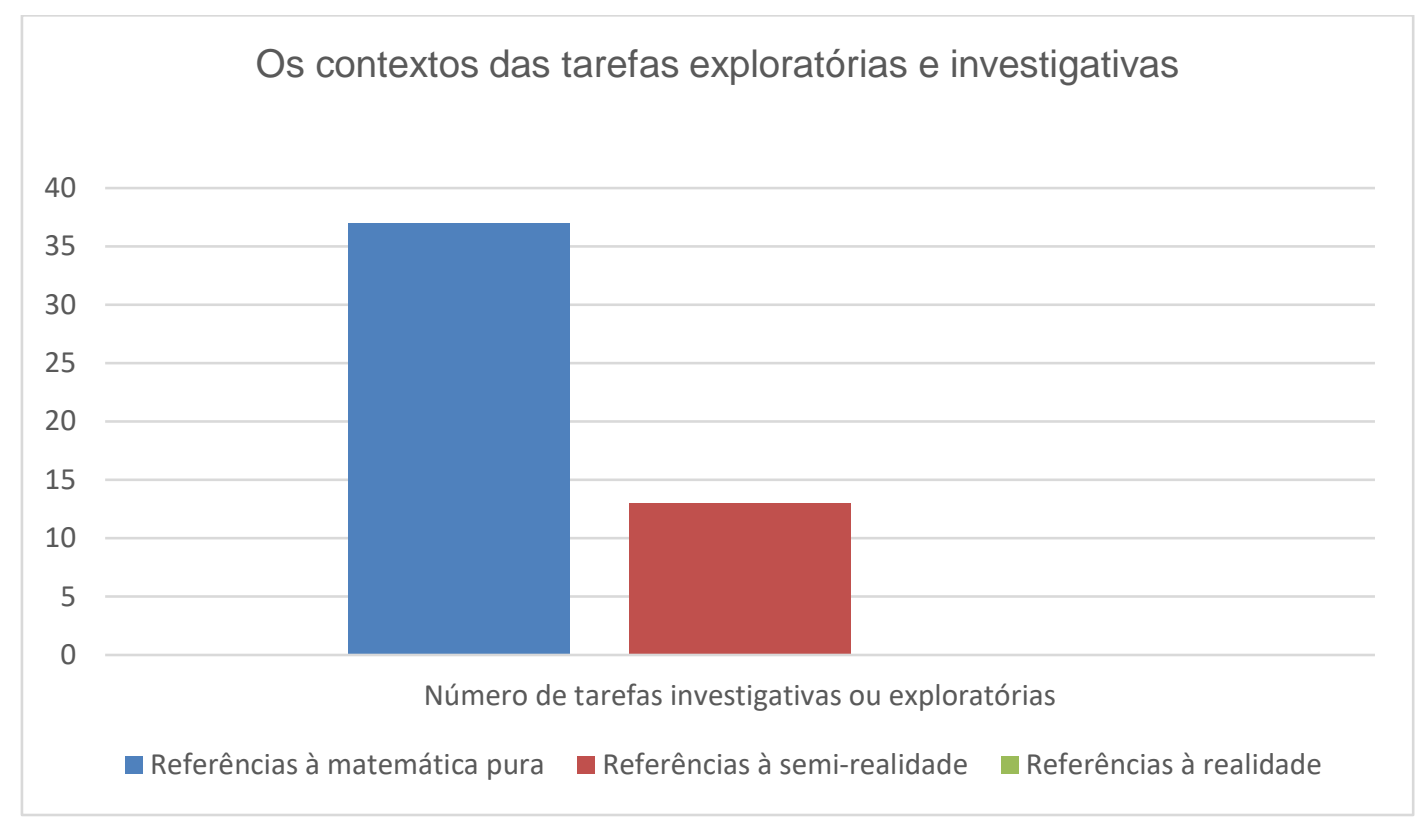

Gráfico 2: Os contextos das tarefas exploratórias e investigativas Fonte: os autores

Nota-se um número superior de tarefas com referências à matemática pura em relação às outras duas. Pensamos que há no mínimo dois motivos para isso: 1) as tarefas com referências à semirrealidade e à realidade tendem a ser consideradas tarefas de Resolução de Problemas ou de Modelagem Matemática, 2) os objetos matemáticos são ideais.

As tarefas com referências à realidade são geralmente classificadas por alguns autores (SANT'ANA, A. A. SANT'ANA, M. F. 2009) como tarefas de Modelagem Matemática. A Modelagem permite a alunos e professores analisar situações advindas da realidade através da Matemática buscando entender como funciona a sociedade em que vivemos e com isso fazer críticas objetivando atuar ativamente nela.

Outro motivo para a predominância de tarefas que fazem referência ao contexto puramente matemático é decorrente da própria natureza do conhecimento matemático. Os objetos matemáticos existem apenas no mundo das ideias, no 
mundo real temos tão-somente representações desses e assim torna-se difícil contextualizá-los com a realidade ou com uma semirrealidade, já que em alguns casos corre-se o risco de colocar obstáculos ao aprendizado dos alunos ou mesmo de perder algumas propriedades, quando não estamos lidando com os objetos ideais.

No tocante aos conteúdos estruturantes propostos pelas Diretrizes Curriculares da Educação Básica da Rede Pública do Estado do Paraná (2008), as tarefas analisadas abordam conteúdos de Números e álgebra, Grandezas e medidas, Geometrias, Funções e Tratamento da informação, conforme o Gráfico 3 a seguir:

\section{Conteúdo das tarefas de Investigação Matemática}

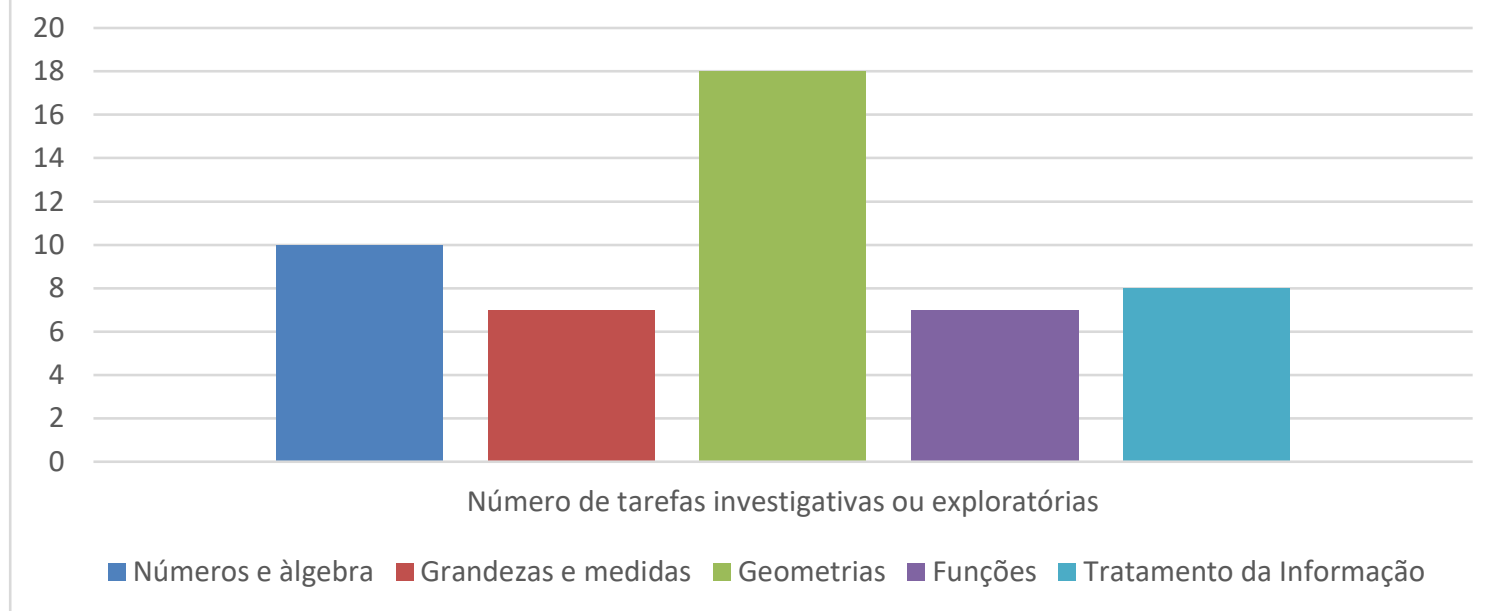

Gráfico 3: Conteúdo das tarefas de Investigação Matemática Fonte: os autores

Percebe-se um número maior de tarefas envolvendo conteúdos de Geometria. Um possível motivo é que a geometria é marcada pela intuição e visualização. Nesse sentido, Abrantes (1999, p.4) afirma:

Fazendo apelo à intuição e à visualização e recorrendo, com naturalidade, à manipulação de materiais, a geometria torna-se, talvez mais do que qualquer outro domínio da Matemática, especialmente propícia a um ensino fortemente baseado na realização de descobertas e na resolução de problemas, desde os 
níveis escolares mais elementares. Na geometria, há um imenso campo para a escolha de tarefas de natureza exploratória e investigativa, que podem ser desenvolvidas na sala de aula, sem necessidade de um grande número de prérequisitos e evitando, sem grande dificuldade, uma visão da Matemática centrada na execução de algoritmos e em "receitas" para resolver exercíciostipo.

Além disso Abrantes (1999) afirma que tanto na geometria plana como na espacial, seus objetos são munidos de diversas propriedades, que podem ser percebidas por meio de regularidades e conexões. As inúmeras regularidades nos objetos geométricos propiciam aos alunos levantar questões, formular conjecturas, testá-las e validar suas hipóteses. Também há a oportunidade de se discutir as definições matemáticas avaliando as consequências de adotá-las de um jeito ou de outro e de compreender a essência e o valor das demonstrações na Matemática.

Abrantes (1999) citando Freudenthal (1973) traz dois argumentos para utilizar tarefas de Investigação Matemática para ensinar geometria:

Por um lado, as descobertas geométricas, sendo feitas também "com os próprios olhos e mãos, são mais convincentes e surpreendentes"; por outro lado, salientando a necessidade de explicação lógica das suas conclusões, a geometria pode fazer sentir aos alunos "a força do espírito humano, ou seja, do seu próprio espírito" (ABRANTES, 1999, p. 3).

No tocante a classificação dada por Ponte (2003) acerca de tarefas exploratórias e investigativas, revela-se que os trabalhos, em sua grande maioria, classificam as tarefas apresentadas como investigativas, entretanto como mencionado em nossa análise a maior parte delas são exploratórias. Alguns poucos trabalhos, tratavam das tarefas exploratórias e investigativas sem distinções.

Por fim, identificamos tarefas assumidas como tarefas de Investigação Matemática, mas que apresentavam características de problemas, exercícios e de tarefas de Modelagem Matemática e Resolução de Problemas, conforme exemplos do Quadro 2 abaixo.

\begin{tabular}{|l|l|}
\hline Exemplo $1^{4}$ & $\begin{array}{l}\text { Se eu colocar } 100 \text { reais na poupança hoje, e não mexer, quanto vou ter } \\
\text { depois de } 5 \text { meses? A taxa de juros é } 0,5 \% \text { ao mês }\end{array}$ \\
\hline
\end{tabular}

\footnotetext{
${ }^{4}$ (BONA, 2013)
} 


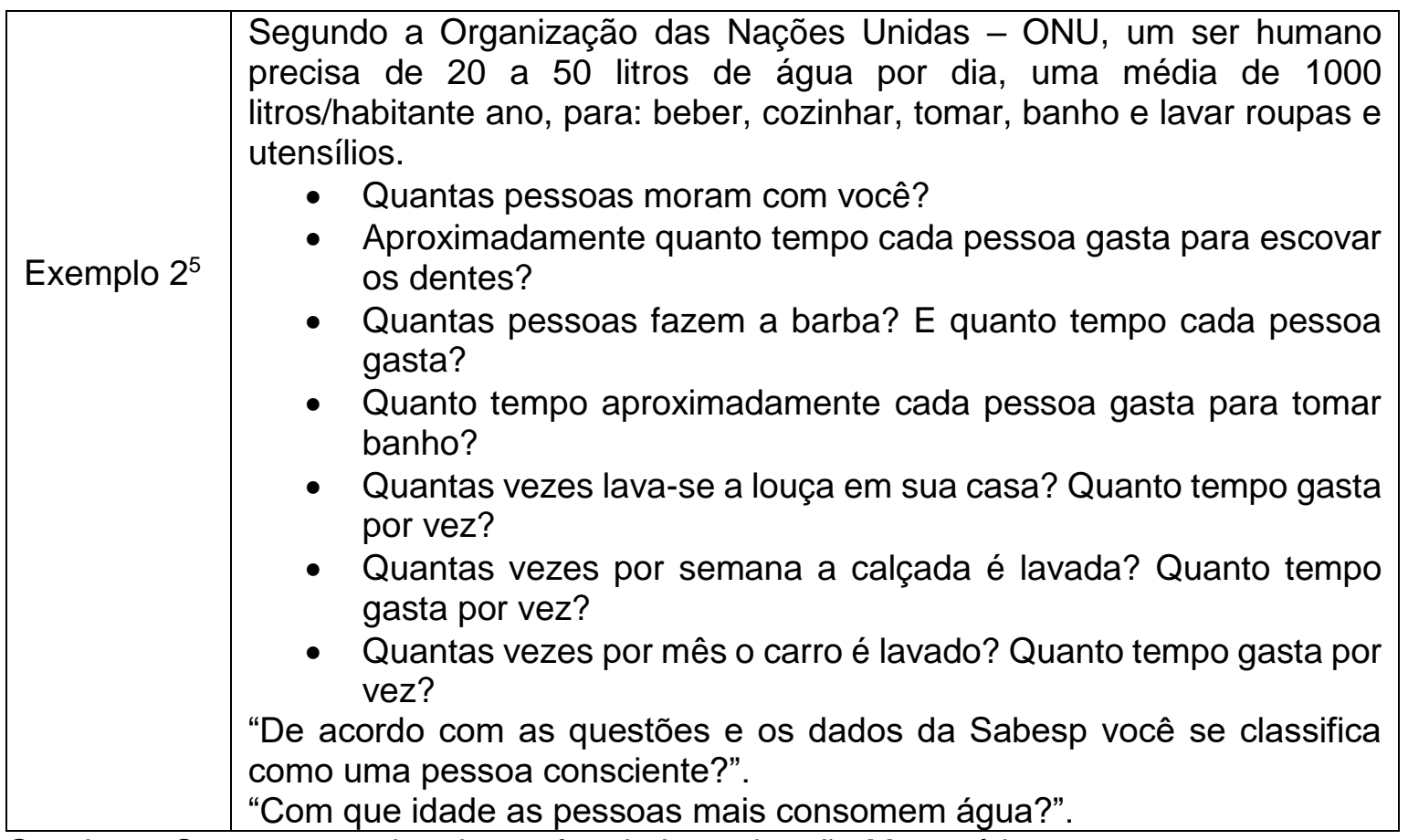

Quadro 2: Contra-exemplos de tarefas de Investigação Matemática

Fonte: os autores

\section{Algumas considerações}

Em face do percebido inferimos que as tarefas analisadas e por nós classificadas como investigativas não apresentaram questões a serem respondidas. Essas questões fazem parte do trabalho do aluno que deverá formulálas conforme seu interesse. Já as tarefas por nós classificadas como exploratórias apresentaram-se compostas por encaminhamentos que induzem 0 aluno a perceber algo que sempre acontece ou não, as questões seguintes o induzem a concluir e generalizar os resultados identificados, ou seja, esse tipo de tarefa propõe ao aluno alguns encaminhamentos/passos para a investigação.

Concordamos com Ponte (2003) ao classificar as tarefas em exploratórias e investigativas com vistas à abertura, à estrutura e ao contexto referencial, porém discordamos que o grau de dificuldade e o tempo requerido para a sua resolução/exploração sejam fatores que possam determinar se uma tarefa é exploratória ou investigativa. Sobre isso Pinheiro (2013, p. 51) nos diz que "um

5 (NASCIMENTO, 2013) 
aluno ao deparar-se com uma atividade do tipo pode não sentir-se desafiado, achar tudo muito óbvio, o que desestabilizaria a concepção de dificuldade agregada a tais atividades" e saliente-a: "O grau de dificuldade, não se dá somente pela tarefa em si, mas também, pelo como o aluno a recepciona" (PINHEIRO, 2013, p. 51).

Uma vez que o grau de dificuldade se mostra dependente do investigador e das relações que este tem com a matemática, com a Investigação Matemática e com os modos de ser e estar no mundo, a classificação das tarefas não pode ser determinada apenas e com ênfase no grau de dificuldade que ela apresenta.

Em geral, os trabalhos analisados são oriundos de práticas pedagógicas com a Investigação Matemática. Há nesse modo operante, uma inclinação dogmática àquilo que está posto na literatura. Nesse sentido, não é comum que a própria Investigação Matemática ou alguns de seus aspectos, sejam postos em suspensão e questionados. Há um fazer amparado pela teoria que se torna novamente teoria ao ser tematizado nas comunicações científicas, entendidas aqui como registro de inovações, descobertas e avanços em determinado tema, nos relatos de experiência e nos minicursos ofertados.

Embora isso seja compreensível dada a natureza e os objetivos de cada trabalho, pode ser prejudicial ao trabalho e ao entendimento da Investigação Matemática. Um exemplo é quando alguns autores dos trabalhos publicados no XI e XII ENEM assumiram tarefas de Modelagem Matemática como tarefas de Investigação Matemática. Também quando assumem tarefas de Investigação Matemática sem atentar-se ao caráter exploratório ou investigativo que, por vezes, apareceu compreendido erroneamente.

Nesse sentido advertimos a necessidade de o contato com a teoria, em termos gerais, acontecer minimamente situada em uma discussão de cunho epistemológico, para que seja possível "transcender a fronteira das práticas que, em geral, se caracterizam como relatos de experiências e buscar teorizações mais latas que fortaleçam, refinem e até mesmo reformulem aquilo que é tomado como posto no tocante à Investigação Matemática" (WICHNOSKI, KLÜBER, 2017b, p. 181). 
A predominância de tarefas exploratórias tem muito a ver com a natureza desses trabalhos, que conforme mencionamos, é pedagógica, advinda da prática de sala de aula. É comum que ao planejar a sua prática, solo das discussões da maioria dos trabalhos analisados, o professor atenda às necessidades dos seus alunos e as condições que the são propícias, adequando-a intuitivamente ao seu contexto e às suas possibilidades. Isso pode explicar, em partes, a predominância das tarefas exploratórias, que embora de Investigação Matemática, são mais diretivas e parecidas com tarefas corriqueiras de matemática.

Durante a construção deste trabalho outras interrogações se presentificaram. Uma delas diz respeito às diferenças entre as tarefas de Investigação Matemática, Resolução de Problemas e Modelagem Matemática, de outro modo, nos perguntamos: há especificidades que permitam distinguir uma tarefa de Investigação Matemática das tarefas de Modelagem Matemática? E de Resolução de Problemas? Estas interrogações se apresentam a nós e a quem se interessar, como propulsoras de trabalhos futuros.

\section{Referências:}

ABRANTES, Paulo. Investigações em Geometria na Sala de Aula. In: VELOSO, Eduardo; FONSECA, Helena; PONTE, João Pedro da; ABRANTES, Paulo. (Orgs.). Ensino da Geometria no Virar do Milénio, Lisboa: DEFCUL, 1999. Disponível em:<http://www.rc.unesp.br/igce/demac/maltempi/cursos/curso3/Artigos/Artigos_arquivos/ p_153-167.pdf >. Acesso em: 06 jun. 2018.

BONA, Aline Silva de. Ações de investigação na aula de matemática. In: ENEM ENCONTRO NACIONAL DE EDUCAÇẪO MATEMÁTICA, 11., 2013, Curitiba. Anais.... [S. I.]: SBEM, 2013. p. 1 - 10. Disponível em: < http://sbem.web1471.kinghost.net/anais/XIENEM/pdf/1066_388_ID.pdf>. Acesso em: 04 maio 2018.

FONSECA, Helena; BRUNHEIRA, Lina; PONTE, João Pedro da. As actividades de investigação, o professor e a aula de matemática. Actas do ProfMat 99, Lisboa: APM, 1999.

GERHARDT, Tatiana Engel; SILVEIRA, Denise Tolfo (Org.). Métodos de pesquisa. Porto Alegre: Ufrgs, 2009.

GIL, Antônio Carlos. Métodos e técnicas de pesquisa social. 5. ed. São Paulo: Atlas, 1999. 
MINAYO, Maria Cecília de Souza (org.). Pesquisa Social. Teoria, método e criatividade. 18 ed. Petrópolis: Vozes, 2001.

NASCIMENTO, Alessandra Cristina do. MERLI, Renato Francisco. O ensino de estatística por meio de uma atividade investigativa - o consumo excessivo de água. In: ENEM - ENCONTRO NACIONAL DE EDUCAÇÃO MATEMÁTICA, 11., 2013, Curitiba. Anais.... [S. I.]: SBEM, 2013. p. 1 - 10. Disponível em: <http://sbem.web1471.kinghost.net/anais/XIENEM/pdf/658_536_ID.pdf>. Acesso em: 04 maio 2018.

PARANÁ. Secretaria de Estado da Educação. Departamento de Educação Básica. Diretrizes Curriculares da Educação Básica - Matemática. Curitiba: SEED, 2008.

PINHEIRO, J. M. L. A aprendizagem significativa em ambientes colaborativoinvestigativos de aprendizagem: um estudo de conceitos de geometria analítica plana. 2013. 202 f. Dissertação (Mestrado) - Programa de Mestrado Profissional em Educação Matemática, UFJF, Juiz de Fora, 2013.

PONTE, João Pedro da. Explorar e Investigar em Matemática: Desafio para Estudantes e Professores. Movimento, 14, 80-96, 2006.

. Gestão Curricular em Matemática. In: O professor e o Desenvolvimento Curricular. Lisboa: APM, 2005.

; BROCARDO, Joana; OLIVEIRA, Hélia. Investigações matemáticas na sala de aula. 3 ed. Belo Horizonte: Autêntica, 2013.

Investigar, ensinar e aprender. Actas do ProfMat 2003 (CD-ROM, pp. 25-39). Lisboa: APM, 2003.

SANT'ANA, Alvino Alves; SANT'ANA, Marilaine de Fraga. Uma experiência com a elaboração de perguntas em Modelagem Matemática. VI Conferência Nacional sobre Modelagem na Educação Matemática. Londrina: 2009.

SKOVSMOSE, Ole. Cenários para investigação. Bolema. n. 14, p. 66 - 91. Rio Claro: 2000.

WICHNOSKI, Paulo; KLÜBER, Tiago Emanuel. Investigações matemáticas na Educação Matemática: uma experiência na formação inicial de professores. Revista de Educação Matemática, São Paulo, v. 15, n. 18, p. 69-83, jan. /abr. 2018.

. Considerações sobre práticas de Investigação Matemática empreendidas e relatadas por professores em formação. RPEM, Campo Mourão, v.6, n.11, p.161-178, jul.-dez. 2017a.

Um Exercício Filosófico Sobre o Trabalho do Professor de Matemática com a Investigação Matemática. BoEM, Joinville, v.5. n.9, p. 179-194, ago./dez. 2017b. 
Um olhar lakatosiano sobre a tendência Investigação Matemática. REVEMAT. Florianópolis (SC), v.10, n. 1, p. 65-80, 2015.

\section{Anexos}

\section{Tarefas Investigativas}

O uso e a elaboração da investigação matemática na formação de professores/p.5 http://sbem.web1471.kinghost.net/anais/XIENEM/pdf/1446 619 ID.pdf Mediação do professor em investigações estatísticas/p.8 http://sbem.web1471.kinghost.net/anais/XIENEM/pdf/2446 1415 ID.pdf Trabalhando geometria fractal no ensino médio, por meio de práticas investigativas/p.6 http://sbem.web1471.kinghost.net/anais/XIENEM/pdf/161 2039 ID.pdf Uma investigação matemática sobre as regularidades das potências de expoente três e suas relações/p.5 http://sbem.web1471.kinghost.net/anais/XIENEM/pdf/222 61 ID.pdf O clássico... A investigação matemática... E o PIBID - IFC/p.5-6 http://www.sbembrasil.org.br/enem2016/anais/pdf/7299 3732 ID.pdf Quadro 3: Tarefas investigativas encontradas nos trabalhos do XI e XII ENEM Fonte: os autores

\section{Tarefas Exploratórias}

Excursão de férias: uma investigação focada em funções de $1^{\circ}$ grau/p.4-5 http://sbem.web1471.kinghost.net/anais/XIENEM/pdf/36 421 ID.pdf

O software geogebra e o trabalho com atividades investigativas na formação de professores/p.5

/http://sbem.web1471.kinghost.net/anais/XIENEM/pdf/981 263 ID.pdf

O uso e a elaboração da investigação matemática na formação de professores/p.5-7

http://sbem.web1471.kinghost.net/anais/XIENEM/pdf/1446 619 ID.pdf

Reflexões sobre a implementação de uma tarefa sobre triângulos/p.11-13

http://sbem.web1471.kinghost.net/anais/XIENEM/pdf/2663 1986 ID.pdf

Construindo conjecturas: um olhar sobre o ensino com a investigação matemática/p.5-9 http://sbem.web1471.kinghost.net/anais/XIENEM/pdf/1613 1577 ID.pdf

A fórmula de Pick em uma experiência pedagógica com atividades de investigação matemática/p.5

http://sbem.web1471.kinghost.net/anais/XIENEM/pdf/2375 598 ID.pdf

Análise de abordagens metodológicas presentes no SARESP e uma proposta de atividades investigativas a partir de questões desse exame/p.9-11

http://sbem.web1471.kinghost.net/anais/XIENEM/pdf/323 180 ID.pdf

Atividades investigativas de probabilidade em livro didático: uma leitura de futuros professores de matemática/p.6-7

http://sbem.web1471.kinghost.net/anais/XIENEM/pdf/2249 1279 ID.pdf

Educação matemática: investigação e modelagem matemática com foco no poder das mídias na moda/p.10-12

http://sbem.web1471.kinghost.net/anais/XIENEM/pdf/908 534 ID.pdf

Explorando o conceito de quadriláteros por meio de uma tarefa investigativa/p.4-7 http://sbem.web1471.kinghost.net/anais/XIENEM/pdf/135 2001 ID.pdf Idosos em conversas sobre regularidades matemáticas utilizando calculadoras/6-8/ http://sbem.web1471.kinghost.net/anais/XIENEM/pdf/717 256 ID.pdf 
Investigação matemática: uma metodologia para ensinar o teorema de Pitágoras/p.4-5 http://sbem.web1471.kinghost.net/anais/XIENEM/pdf/1602 377 ID.pdf

Investigando em sala de aula: os alunos como investigadores de suas práticas matemáticas/p.2

http://sbem.web1471.kinghost.net/anais/XIENEM/pdf/123 400 ID.pdf

Investigando o número de diagonais de um polígono utilizando o geogebra: um relato de tarefa/p.10

http://sbem.web1471.kinghost.net/anais/XIENEM/pdf/1516 634 ID.pdf

O ensino de matemática: A investigação e a reflexão na aula de matemática/p.4

http://sbem.web1471.kinghost.net/anais/XIENEM/pdf/579 1854 ID.pdf

O software superlogo em atividades investigativas: construindo bandeiras e aprendendo geometria/p.5-9

http://sbem.web1471.kinghost.net/anais/XIENEM/pdf/1027 1565 ID.pdf

O uso da calculadora em sala de aula: uma proposta de atividade investigativa/p.8-10

http://sbem.web1471.kinghost.net/anais/XIENEM/pdf/2145 544 ID.pdf

O uso do software de geometria dinâmica como ação investigativa no ensino da matemática/p.5-8

http://sbem.web1471.kinghost.net/anais/XIENEM/pdf/1291 1527 ID.pdf

Resolução de problemas e investigação matemática/p.10

http://sbem.web1471.kinghost.net/anais/XIENEM/pdf/24 1175 ID.pdf

Trabalhando geometria fractal no ensino médio, por meio de práticas investigativas/p.7

http://sbem.web1471.kinghost.net/anais/XIENEM/pdf/161 2039 ID.pdf

Um objeto de aprendizagem, uma atividade de investigação, diferentes grupos e diferentes significados/p.3-4

http://sbem.web1471.kinghost.net/anais/XIENEM/pdf/3254 1637 ID.pdf

Atividades de investigação matemática na educação infantil/p.5-7

http://sbem.web1471.kinghost.net/anais/XIENEM/pdf/3344 2055 ID.pdf

A aprendizagem de função afim via tarefas exploratórias-investigativas/p.7-8

http://www.sbembrasil.org.br/enem2016/anais/pdf/5615 3050 ID.pdf

Abordagem dialógica e investigativa: uma possibilidade de trabalho com polinômios/p.4-

9

http://www.sbembrasil.org.br/enem2016/anais/pdf/7151 3564 ID.pdf

Investigando propriedades geométricas com o geogebra num projeto de iniciação científica com estudantes do ensino fundamental/p.4 e p.7-8

http://www.sbembrasil.org.br/enem2016/anais/pdf/6944 3061 ID.pdf

O ensino de análise combinatória com atividades investigativas/p.6-8

http://www.sbembrasil.org.br/enem2016/anais/pdf/8111 4069 ID.pdf

Reflexões de professores de matemática ao analisar uma tarefa estatística de natureza exploratória envolvendo a transnumeração/p.5

http://www.sbembrasil.org.br/enem2016/anais/pdf/7199 2889 ID.pdf

A elaboração e implementação de uma tarefa exploratória na perspectiva de um professor de matemática da educação básica/p.12

http://www.sbembrasil.org.br/enem2016/anais/pdf/8188 4062 ID.pdf

Explorar e investigar na EJA/p.7

http://www.sbembrasil.org.br/enem2016/anais/pdf/7474 3203 ID.pdf

Introdução às funções exponenciais: uma abordagem investigativa na sala de aula/p.7

http://www.sbembrasil.org.br/enem2016/anais/pdf/6035 4139 ID.pdf 
Investigação matemática: atividades envolvendo concepções algébricas/p.5-8 http://www.sbembrasil.org.br/enem2016/anais/pdf/5970 3525 ID.pdf Investigações matemáticas em sala de aula: Contribuições de uma Tarefa Investigativa no $1^{\circ}$ Ano do Ensino Médio/p.6-7

http://www.sbembrasil.org.br/enem2016/anais/pdf/6320 2940 ID.pdf

O clássico... A investigação matemática... E o PIBID - IFC/p.6

http://www.sbembrasil.org.br/enem2016/anais/pdf/7299 3732 ID.pdf

Triângulos - implementação de uma tarefa investigativa/exploratória/p.4-6 http://www.sbembrasil.org.br/enem2016/anais/pdf/5468 3293 ID.pdf

Um estudo de função exponencial por meio de tarefas investigativas e a torre de Hanói/p.5-9

http://www.sbembrasil.org.br/enem2016/anais/pdf/5684 2548 ID.pdf

Quadro 4: Tarefas exploratórias encontradas nos trabalhos do XI e XII ENEM

Fonte: os autores 